УДК 821.133.1-31

DOI https://doi.org/10.26661/2414-1135-2021-82-18

\title{
ВЕРБАЛІЗАЦІЯ КОНЦЕПТІВ ПОДІЯ, ПРОСТІР ТА ЛЮДИНА В МЕМУАРНИХ ТЕКСТАХ
}

\author{
Коваленко С. П. \\ старший викладач кафедри романської філологї \\ та порівняльно-типологічного мовознавства \\ Інститут філології \\ Київського університету імені Бориса Грінченка \\ вул. Тимошенка, 13-Б, Київ, Україна \\ orcid.org/0000-0001-7853-1096 \\ sergekovalenko61@gmail.com
} Ключові слова: різнорівневі
концепти, когнітивно-
семантичний простір,
варіативна організація,
текстотвірні концепти,
морально-антропоморфний
ланцџюг розгортання концепту.
Стаття присвячена дослідженню когнітивно-семантичного простору концептів подія, простір та людина в спогадах відомих французьких мемуаристів минулого століття: Симони де Бовуар, Жана Даніеля та Жака Робера. Передбачалося прослідкувати просторову конфігурацію текстових концептів, їх варіативні характеристики та роль у розгортанні текстового змісту мемуарів.

Аналіз текстового масиву різних авторів довів, що особливістю концепту подія є поєднання нейтрально-фактуальної інформації і суб'єктивноавторського ставлення до неї. Це твердження чітко проглядається в концепті подія «Референдум» у мемуарному романі С. де Бовуар «La force des choses II», де загальновідома фактуальна інформація переплетена 3 авторською добіркою концептів емотивного (головним чином, негативного) порядку: поразка, гіркота, радість, спустошення, пригніченість, песимізм, похмурість, відчай, приголомшеність, розчарування, марні сподівання, невідворотність, мара, туга, жах, бунт, скандал, незгода, тривога, депресія, несконцентрованість. Інший категоріальний концепт простір виконує текстотвірну функцію, локалізуючи описувані мемуаристами події просторово (в поєднанні 3 концептом час, що локалізує події темпорально). Така локалізація відбувається шляхом інтенсивної стратифікації різнорівневих концептів: макроконцептів, мезоконцептів, катаконцептів.

Неодмінною складовою частиною всіх мемуарних текстів $є$ мегаконцепт людина, оскільки будь-яке відтворення минулого пов'язане з людською діяльністю: самого автора-мемуариста чи того/тих, кого він описує. Автори досліджуваних мемуарних текстів - загальновідомі, публічні особистості, що володіють високим рівнем мовленнєвої культури, а отже, потужними можливостями впливу на читача. Серед таких засобів впливу слід виділити варіювання текстових концептів темпоральної, просторової чи емотивної семантики. Самі мемуаристи, втім як і численні згадувані ними особистості, асоціативно набули статусу концепту завдяки своїй діяльності, загальновідомості.

Проведене дослідження дало змогу зробити важливий висновок: варіювання різнорівневих концептів мемуарних текстів сприяє їх семантико-когнітивному збагаченню та робить суб'єктивно-авторську позицію мемуариста більш помітною в текстовому просторі мемуарів.

Втім, це дослідження виводить на цілу низку невирішених питань, пов'язаних з інформативною основою мемуарів, когнітивною периферією, динамікою розгортання текстового змісту i, безумовно, 3 мовною грою таких текстів. Усі ці питання чекають подальших студій. 


\title{
VERBALIZATION OF CONCEPTS EVENT, SPACE AND MAN IN MEMOIR TEXTS
}

\author{
Kovalenko S. P. \\ Senior Lecturer at the Department of Romance Philology \\ and Comparative Typological Linguistics \\ Institute of Philology \\ of Borys Grinchenko Kyiv University \\ Tymoshenko str., 13-B, Kyiv, Ukraine \\ orcid.org/0000-0001-7853-1096 \\ sergekovalenko61@gmail.com
}

Key words: multi-level concepts, cognitive and semantic space, variable organization, textforming concepts, moral and anthropomorphic chain of concept deployment.
The article is devoted to the study of the cognitive and semantic space of concepts event, space and man in the memoirs of famous French memoirists of the last century: Simone de Beauvoir, Jean Daniel and Jacques Robert. The goal was to trace the spatial configuration of text concepts, their variable characteristics and role in the development of the text content of memoirs.

Analysis of the texts of various authors proved that the peculiarity of the concept event is a combination of neutral and factual information with author's subjective attitude to it. This statement is clearly seen in the concept event "Referendum" in S. de Beauvoir's memoir novel "La force des choices II", where well-known factual information is intertwined with the author's selection of concepts of emotional (mainly negative) order: defeat, bitterness, joy, desolation, depression, pessimism, gloom, despair, overwhelming, disappointment, vain hopes, inevitability, curse, melancholy, horror, riot, scandal, disagreement, anxiety, depression, lack of concentration. Another categorical concept - space - performs a text-forming function, localizing the events described by memoirists spatially (in combination with the concept time, localizing events temporally). This localization occurs through intensive stratification of multi-level concepts: macroconcepts, mesoconcepts, cataconcepts.

An essential component of all memoir texts is the megaconcept man since any reproduction of the past is associated with human activity: the author himself the memoirist - or the one/those whom he describes. The authors of the studied memoir texts are well-known public figures who have a high level of speech culture and, consequently, powerful opportunities to influence the reader. Among such means of influence, it is necessary to distinguish variations in textual concepts of temporal, spatial, or emotional semantics. The memoirists themselves, however, as well as the numerous personalities they mention, associatively acquired the status of a concept due to their activities, their general publicity.

The study allowed us to draw an important conclusion: variation of multi-level concepts of memoir texts contributes to their semantic and cognitive enrichment and makes the author's subjective position of the memoirist more noticeable in the text space of memoirs.

However, this study leads to a number of unresolved issues related to the informative basis of memoirs, cognitive periphery, dynamics of text content deployment, and, of course, the word play of this type of texts. All these questions are waiting for the future research.
Постановка проблеми. Когнітивна поетика художнього тексту, як доводять сучасні дослідження, має потужний вплив на суміжну область мемуаристику. Неодмінний елемент мемуарних текстів - їх документальна основа - дещо обмежує авторську творчу складову частину. Проте досліджувані доробки належать до творів високої мов- леннєвої культури інтелектуальної еліти Франції і за своїм рівнем не поступаються будь-яким художнім. Це дає змогу застосувати до мемуарних текстів систему когнітивно-поетичних підходів художніх текстів.

Мемуарні тексти мають специфіку, оскільки пов'язані з особливостями пам'яті автора, часо- 
вою віддаленістю від моменту події тощо. Хронологія подій плутається, втрачаються зв'язки між ними, враження тьмяніють, що відбивається на жанровій багатогранності та змістовній насиченості мемуарних текстів.

Метою статті $\epsilon$ дослідження ролі різноманітних текстових концептів у творах французької мемуаристики XX століття, зокрема їх щільності та інтенсивності перемежовування для розгортання текстового змісту мемуарів.

Аналіз досліджень. У своєму дослідженні концептуального простору мемуарних текстів ми спираємося на положення концептів та концептосистем у когнітивно-дискурсивній парадигмі лінгвістики, розробленої А.М. Приходьком [4]. У статті також враховувалися наукові позиції О.П. Воробйової [1], А.А. Галича [2], О.М. Кагановської [3].

Виклад основного матеріалу. Концептуальна структура сучасних мемуарних текстів містить як загальнодиверсифіковані концепти художнього типу, так і власне мемуарні. Текстовий концепт варто розглядати як «кодоване мовленнєворозумове утворення змістового плану, яке зумовлене багатосмисловою напруженістю художнього [i мемуарного зокрема - K.C.] тексту, характеризується надкатегоріальністю й імплікує сукупність ознакових рис художнього [мемуарного] твору» $[3$, c. 15$]$.

Фундаментальними текстотвірними концептами мемуарних текстів С. де Бовуар, Ж. Даніеля та Ж. Робера виявилися концепти чАС, ПРостІР, подІя та ЛюдинА.

У кожного 3 цих авторів текстовий масив містить комплекси, як обов'язкові концепти, так і специфічні, продиктовані індивідуально- авторськими настановами.

Когнітивно-семантичний простір концепту подІя. Стосовно концепту подІя варто зазначити його універсальність, з одного боку, і специфічність - 3 іншого. Універсальність подій детермінується в часовій і просторовій локалізації, їх чергуванні, а специфічність - в індивідуально-авторському ставленні до цих подій. Так, у своїх спогадах «La force des choses II» C. де Бовуар розповідає про відомий факт референдуму у Франції 28 вересня 1958 року з приводу прийняття нової Конституції, за результатами якого французи висловилися за і започаткували існування П'ятої Республіки. У нейтральному плані концепт подія «Референдум» - це факт, що мав місце там і тоді. Друга складова частина концепту подІя - авторське ставлення до неї як до події, в якій перетинаються вкрай негативні концепти як морального, так і антропоморфного порядку.

Прослідкуємо весь морально-антропоморфний ланцюг розгортання концепту подІя «Рефе- рендум»: Nous parlons de l'Algérie, évidemment. Et du référendum. Il est extrêmement pessimiste (концепт ПЕСимізм) (передчуття поразки напередодні референдуму). Tout le monde attend dimanche : 60\%? 70\%? Nous parions pour 65 à $68 \%$ : plutôt 68 . Ensuite ce sera la campagne électorale, qui s'annonce mal. Eh bien, nous l'avons connu, le goût de la défaite (концеПт ПОРАЗКА), et il était plutôt amer (концепт гіркотА). C'était une bien belle journée, dorée, légère, les gens allaient voter avec le sourire (протилежність ставлення до результатів референдуму тих, хто висловився на ньому ТАК, - концеПт РАДІСТь), les bureaux avaient l'air presque vides, malgré l'énorme participation, sans doute parce que c'était très bien organisé. ... On s'est promenés, mollement, et assis à une terrasse près de Saint-Michel : on se sentait démobilisés, vacants (концепт СпустоШення); on n'était pas très anxieux : entre 62 p. 100 et $68 \mathrm{p} .100$, les jeux semblaient faits, ... . Lanzmann est arrivé vers minuit, catastrophé (концепт пРигнІЧЕНІСТЬ) déjà, ne voulant pas trop le montrer parce que Sartre l'accuse souvent de pessimisme (концепт ПЕСимізм). Les résultats qu'on avait étaient consternants (концепт ПРИГнІченІСть): plus de 80 p. 100. Sartre a été dormir. Nous sommes passés à France-Soir, bourdonnant d'activité : on avait toute la province, sauf Marseille, et ça donnait plus de $80 \mathrm{p}$. 100. On est rentrés, sinistres (концепт похмурість), et on a recommencé, comme au 13 mai, la ronde des coups de téléphone. D'abord Péju, qui avait un tas de chiffres précis, navrants (концепт ПРИГНІченІсть). A L'Humanité, Lanzmann a eu T. et il a demandé : «Mais les communistes ont trahi : comment est-ce possible ?» et l'autre a répondu sombrement (концепт похмурість): «Lis l'article de ton ami Sartre. Je me suis mise à pleurer (концепт ВІдчАй), je n'aurais pas cru que ça me ferait un tel coup (концепт ПРиголОМшенІсть); j'ai encore envie de pleurer (концепт вІдчАй) ce matin. C'est plutôt affreux d'être contre tout un pays, le sien, on est déjà en exil (концепт пригнгченість). On a téléphoné au père de L. ; il a dit que sur les Champs-Elysées, il y avait tous les cagoulards qui exultaient. Leur joie est presque aussi dure à supporter que la déception (концепт РОЗЧАРУВАННЯ) de ceux de notre bord. Il y a eu un instant de faux espoir (концепт МАРНІ СПОДІВАННЯ): d'après Europe 1, aux dernières nouvelles on était à 72 p. 100 seulement. Mais c'était une erreur, Paris a voté oui à $77 \mathrm{p}$. 100. Il y en a beaucoup, énormément, qui ne savent pas ce qu'ils font, ... . Seulement, c'est irréversible (концепт НЕВІдвоРОтНІСть); avant qu'ils s'aperçoivent que l'espoir n'est pas là, combien d'années? ... Des cauchemars (концепт МАРА) toute la nuit. Et je me sens en morceaux (концепт спустоШення). Quand j'ai acheté France-Soir, Libération, que je les ai ouverts place Denfert-Rochereau, ça m'a rappelé la guerre (концепт вІйна), quand 
j'ouvrais les journaux et que je fondais en larmes: "Les Allemands sont entrés en Belgique.» ... mais j'ai senti presque la même détresse (концепт тугА). Que Libération était sombre ! (концепт похмурість) L'Humanité aussi, parait-il, mais il n'en restait plus. J'ai téléphoné. Sartre ne s'attendait pas à ça. Moi j'ai la mort dans l'âme (концепт СМЕРТЬ). C'est mon département, la Corrèze, qui a le mieux voté ! Ce pauvre pays de bruyères et de châtaigniers, dans mon enfance (концепт дитинство) il était déjà radical. Cette horreur (концепт ЖАХ) qu'ont les gens, du Parlement. Sartre indique dans son article qu'on regarde les députés comme des «paresseux» et comme opposant à l'exécutif des espèces de mutineries (концепт Бунт). Il y a d'autres choses encore. D'abord de vieux relents de scandales (концепт СКАНДАЛ): Panama, Oustric, Stavisky; ... Défaite sinistre (концеПт ПОРАЗКА) parce que ce n'est pas celle d'un parti, d'une idée, mais un désaveu (концепт НЕзгодА) par 80 p. 100 des Français de tout ce que nous croyions et voulions pour la France. Un désaveu (концепт НЕЗГОДА) d'eux-mêmes, un énorme suicide collectif (концепт САмОГУБСТВо). ... Journée assombrie par le référendum (концепт похмурість) et la maladie de Sartre qui souffre de la tête, qui ne veut pas voir le médecin avant samedi, qui m'inquiète. Je fais des cauchemars (концепт МАРА) et toute la journée je suis dans le malaise (концепт ТРИвОГА) ... Jours sombres (концепт похмурість). La lecture de L'Express est déprimante (концепт ДЕПРЕСІя): un numéro de défaite acceptée (концепт ПОРАЗКА) et de diversion. L'Observateur se tient mieux ... . ... L'avenir n'a pas de figure. On se sent en chômage (концепт БЕзРоБІття), démobilisés (концепт спуСТОШЕННЯ), déconcentrés (КонцеПТ НЕСКОНцЕНтРОВАнІСть) ... . Vraiment assez horribles journées (концепт ЖАХ). ... Horribles journées (концепт ЖАХ). Surtout samedi ... Dimanche, hier : un long cauchemar ouaté (концепт мАРА) !... Sortie de ce cauchemar (концепт МАРА), de cette maladie (концепт ХвоРОБА). Il faur être déjà émoussé par la vieillesse (концепт СТАРІСть) pour la supporter ... . ... J'ai mis les feuilles dans une chemise sur laquelle j'ai écrit : Journal d'une défaite (концепт ПОРАЗКА) [6, c. 224-233].

3 цього прикладу випливає, що концепт подія «Референдум», з огляду на позицію автора-мемуариста, пов'язаний із цілою низкою концептів еМОціЙНОГО ПОРЯДКУ (ПОРАЗКА, ГІРКОТА, РАДІСТЬ, СПУСТОШЕННЯ, ПРИГНІЧЕНІСТЬ, ПЕСИМІЗМ, ПОХМУРІСТЬ, ВІДЧАЙ, ПРИГОЛОМШЕНІСТЬ, РОЗЧАРУВАННЯ, МАРНІ СПОДІВАННЯ, НЕВІДВОРОТНІСТЬ, МАРА, ТУГА, ЖАХ, БУНТ, СКАНДАЛ, НЕЗГОДА, ТРИВОГА, ДЕПРЕСІЯ, НЕСКОНЦЕНТРОВАНІСТЬ) (ДИВ. ТабЛ. 1):

Ця порівняльна таблиця двох перспектив концепту подія «Референдум» свідчить про превалювання авторської позиції (тих, хто ПРОТИ) за допомогою цілого комплексу негативних концептів емоційного порядку, на відміну від не-авторської позиції (тих, хто висловився ЗА), де лише одного разу зустрічається концепт РАдІсть. Мета такої щільності негативних концептів полягає не тільки в тому, щоб підкреслити гіркоту своєї поразки, але й довести читачеві (нерідко - своєму опонентові), що авторська позиція правильна, а інша - хибна, навіть згубна (величезне колективне самогубство).

Також привертає увагу в цьому відрізку присутність біовітальних концептів дитинство та СТАРІСТь. С. де Бовуар багаторазово звертається до них у своєму мемуарному циклі, бо останній охоплює весь ії життєвий шлях, з одного боку, а 3 іншого - починаючи з їі спогадів «La force des choses», авторка переймається питанням старості, яке дедалі стає для неї дедалі більш вразливим: La force des choses I: Le temps se raccourcit à mesure qu'on vieillit... [5, c. 348$] ;$... je vieillis, le monde change, mon rapport avec lui varie... [5, c. 378]; La force des choses II: Qui vois-je? Vieillir c'est se définir et se réduire. Je me suis débattue contre les étiquettes; mais je n'ai pas pu empêcher les années de m'emprisonner... [6, c. 503-504]; La vieillesse: de loin on la prend pour une institution: mais ce sont des gens jeunes qui soudain se trouvent être vieux. Un jour, je me suis dit: J'ai quarante ans! Quand je me suis réveillée de cet étonnement, j'en avais cinquante. ... Au fond du miroir la vieillesse guette; et c'est fatal, elle m'aura [6, c. 505]; Tout compte fait: Moi, l'évidence de mon vieillissement $m$ 'a frappé entre 1958 et 1962 [8, c. 165]; Sur le sort des vieillards dans les sociétés historiques, ... ils sont passés sous silence [8, c. 184].

Когнітивно-семантичний простір концепту пРОстІР. На мегаконцептуальному рівні варто також зазначити категоріальний концепт пРостІР, який виконує поруч із концептом ЧАС головну текстотвірну функцію в будь-якого автора-мемуариста. події, що відбуваються в певний чАс у мемуарному тексті, завжди просторово чітко локалізовані. Просторова локалізація відбувається на двох макроконцептуальних рівнях: мІСцЕ і НАПРямок. У межах макроконцепту мІсцЕ прийнято виділяти МеЗОКОНЦЕПТИ ВЕРТИКАЛЬ В ГОРИЗОНТАЛЬ, ПЕРЕД ЗАД, ПРАВО і ЛІВО, а НАПРЯМОК ПОДіЛЯєТЬСЯ На ВГОРУ і ВНИЗ, ВПЕРЕД і НАЗАД, ВЛІВО і ВПРАВО. На НеПОДіЛЬному етапі катаконцептів (або власне концептів) зустрічаються слова та вирази просторової семантики: С. де Бовуар «La force de l'âge»: Je grimpais (вгору) sur toutes ses rocailles, je rôdais dans toutes ses ruelles (гоРИЗОНТАЛЬ), je respirais le goudron et les odeurs du Vieux-port, je me mêlais aux foules de la Cannebière, je m'assis dans des allées (горизонТАЛЬ), dans des jardins (ГОРИЗОНТАЛЬ), sur des cours paisibles (гоРИзОНТАЛЬ) où la provinciale odeur des feuilles mortes étouffait celle du vent marin... 
Таблиця 1

Порівняльна таблиця концепту ПОДІЯ «Референдум» у мемуарах С. де Бовуар

\begin{tabular}{|c|c|}
\hline $\begin{array}{c}\text { Ti, хто висловилися } \\
\text { ЗА }\end{array}$ & Ті, хто висловилися ПРОТИ \\
\hline $\begin{array}{l}\text { КонцеПт РАДІСТЬ } \\
\text { (une bien belle } \\
\text { journée, dorée, légère, } \\
\text { les gens allaient voter } \\
\text { avec le sourire) }\end{array}$ & 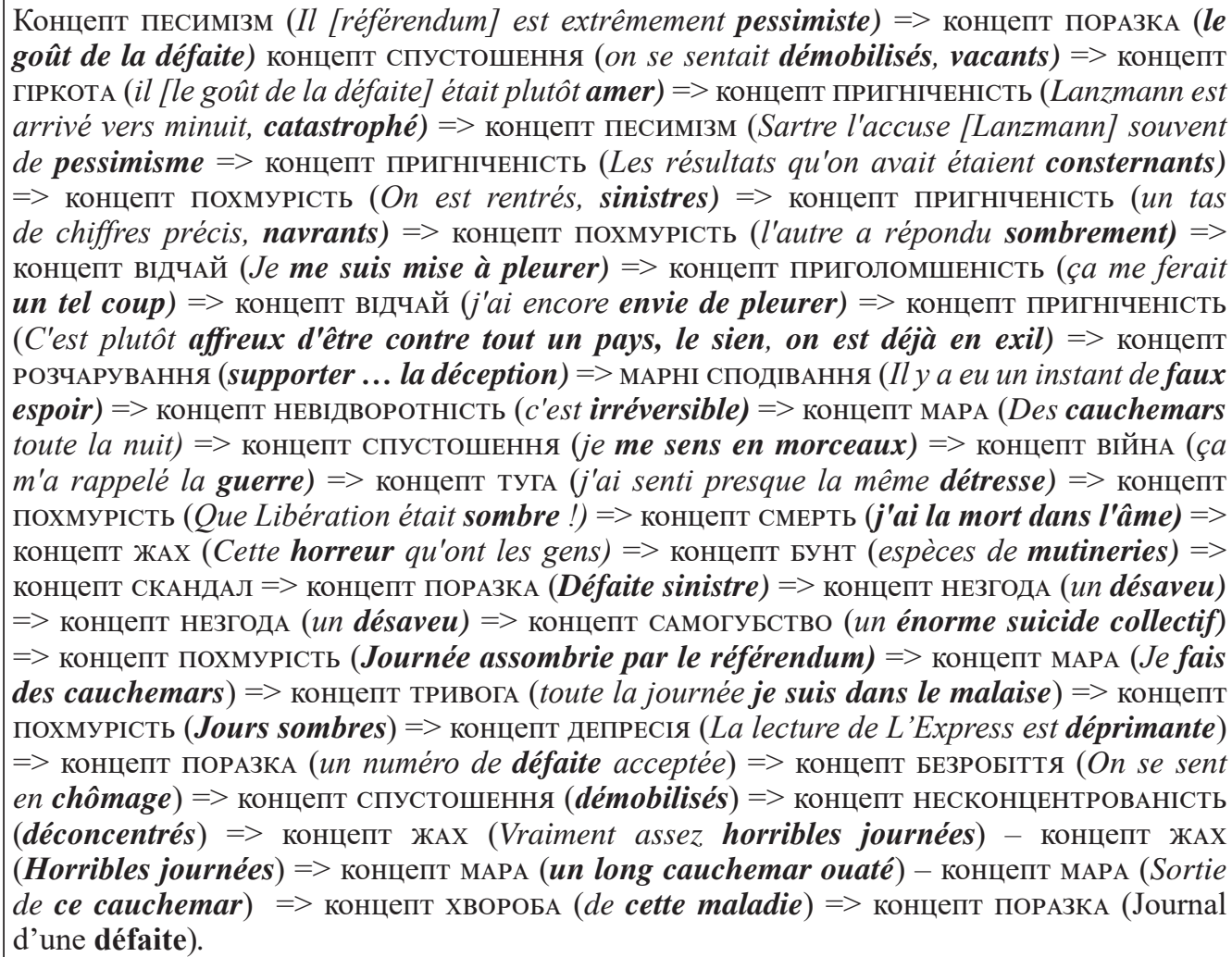 \\
\hline
\end{tabular}

Je ratissais systématiquement la région (горизонТАЛЬ). Je montais sur tous les sommets (ВГОРу) : le Gardauber, le mont Aurélien, Sainte-Victoire, le Pilon $d u$ Roi, je descendis dans toutes les calanques (вниз), j'explorais les vallées, les gorges, les défilées... (ГОРИЗОНТАЛЬ) Je suivis au bord de la mer (ГОРИЗОНТАЛЬ) tous les chemins douaniers au pied des falaises (ГОРИзОНТАЛЬ), le long des côtes tourmentées (гоРИзОНТАль), la Méditerranée n'avait pas cette langueur ... [7, с. 105-106]; Ж. Даніель «Le temps qui reste»: La civilisation arabe, avec toutes ces expressions de grâce que l'on prononce en hommage à celui qui revient d'un bain (НАЗАД), de chez le tailleur (НАЗАД), de chez le coiffeur (НАЗАД), à celui qui s'installe dans une maison nouvelle (ГОРИзОНТАЛЬ), ... En Tunisie, ... (ГОРИзОНТАЛЬ) [9, с. 79-80]; Ж. Робер «Les stars de mes nuits»: A Berlin (горИзОНТАЛЬ), je fus le seul journaliste occidental à descendre dans le bunker de Hitler (вниз). A Milan (горизонтАль), je démasquai l'homme ayant abattu de sa main Mussolini, près du lac de Côme (гоРИзоНТАЛЬ). A Copenhague (гоРИзОНТАЛЬ), je débusquai, dans un grenier (ГОРИзОНТАЛЬ), Céline qu'on croyait mort et enterré. Même à Paris (горизонтАль), fidèle à ma loi, je créai l'événement en fondant avec Boris Vian, à Saint-Germain-desPrés (горизонталь), la paroisse des existentialistes [10, с. 18]; С. де Бовуар «Tout compte fait»:
A travers de beaux paysages de montagne (ВПЕРЕД), un train nous a conduits à Tbilissi (ВПЕРЕД), la capitale de la Géorgie. ... Située sur les deux rives de la Koura (гоРИзОНТАЛЬ) et sur trois côtés entourée de montagnes (гоРИзОНТАЛЬ), elle conserve de beaux monuments et un vieux quartier très plaisant (ГОРИЗОНТАЛЬ): des rues étroites (ГОРИзОНТАЛЬ), en pente raide (вниз), bordées de maisons de bois aux balcons ouvragés (ГОРИзОНТАЛЬ) [8, с. 406].

Когнітивно-семантичний простір концепту людинА. Потужною складовою частиною будьякого мемуарного тексту $є$ категоріальний концепт людинА. До складу цього мегаконцепту входить ряд макроконцептів, таких як внУтРшшнй СВІТ, ВНУТРІШНЯ ЛЮДИНА, СТАН ЛЮДИНИ, ПРИРОДА тощо. Питання семантико-структурної організації концепту людинА все ще чекає свого вирішення, оскільки є надто об'ємним і багатогранним для рамок одного дослідження. До того ж весь концептуальний світ прямо чи опосередковано пов'язаний із цим фундаментальним концептом.

Вивчаючи роль, місце та значущість концепту людинА в мемуарних текстах, ми дійшли висновку, що, окрім спільних для всього текстового світу ознакових рис цього концепту, вимальовуються і специфічні, власне мемуарні характеристики. Перш за все, це стосується самих 
авторів-мемуаристів. Як концепти слід розглядати також і їхні імена, які набули концептуального рівня завдяки своїй життєвій діяльності: письменницькій творчості, журналістській чи суспільній роботі тощо. Так, концепт БОВУАР асоціативно ВИКЛИКає КОНЦеПТИ ПИСЬМЕННИЦЯ, МЕМУАРИСТКА, ФЕМІНІСТКА, ЕКЗИСТЕНЦІАЛІСТКА, ПОДРУГА [ДРУЖИНА] САРТРА (див. рис. 1):

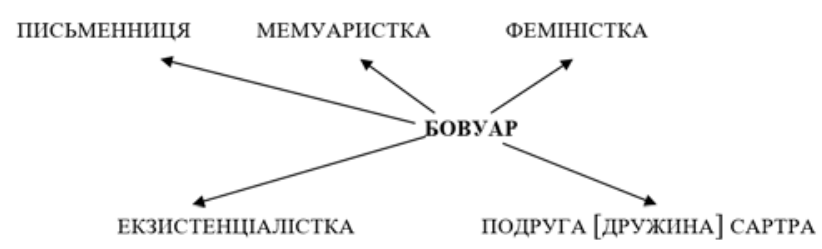

Рис. 1. Схема асоціативних концептів концеПтУ БОВУАР

Концепт ДАНІЕЛЬ має такий вигляд (див. рис. 2):

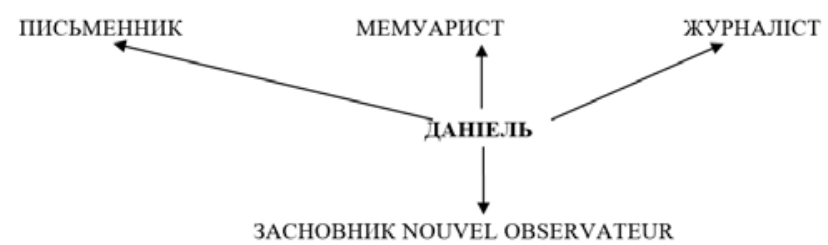

\section{Рис. 2. Схема асоціативних концептів концеПтУ ДАНІЕЛЬ}

Концепт РоБЕР має такий вигляд (див. рис. 3):

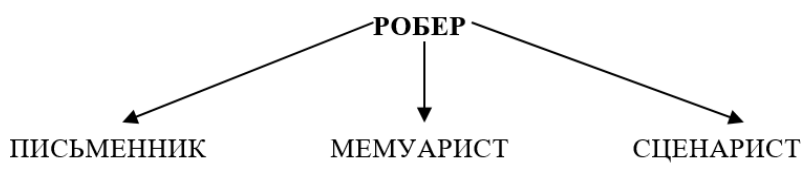

\section{Рис. 3. Схема асоціативних концептів КОНцеПтУ РОБЕР}

Концептуальні поля кожного 3 авторів єднають КОНцеПТИ ПИСЬМЕННИК Та МЕМУАРИСТ: ВСі вОНИ ПиСаЛИ як художні романи, так і власні мемуарні цикли.

Іншою стороною концепту людинА варто розглядати весь мегасвіт реальних персонажів мемуарного простору зазначених авторів-мемуаристів. Кожен персонаж, відомий чи невідомий - це концепт зі складною ієрархією концептуальних елементів, що формують людину як унікальну особистість, як унікальний концепт.

Концепт людинА привернув увагу науковців із самого початку когнітивних досліджень, проте Ім'я як концепт, його місце та роль у системі інших концептів ще чекає свого подальшого дослідження.

Висновки. Варіативна організація концептуального простору мемуарних текстів проявляється в перемежовуванні головних, вищих ієрархічних концептів із концептами більш низького та другорядного рівня ієрархії, які покликані доповнювати та збагачувати семантико-когнітивне наповнення мемуарних текстів.

Усі зазначені характеристики мемуарного жанру викликають жвавий дослідницький інтерес мовознавців. Залишаються невивченими або маловивченими питання, пов'язані 3 інформативною основою мемуарних текстів, їх суб'єктивно-авторським оформленням, суто лінгвістичними засобами перспективації, когнітивною периферією тощо.

\section{ЛІТЕРАТУРА}

1. Воробьева О.П. Лингвистические аспекты адресованности художественного текста : дис. ... д. филол. н. Москва, 1993. 382 с.

2. Галич А.А. Украинская писательская мемуаристика (Природа, эволюция, поэтика) : дис. ... д. филол. н. Киев, 1991. 399 с.

3. Кагановська О.М. Текстові концепти художньої прози: когнітивна та комунікативна динаміка (на матеріалі французької романістики XX століття) : дис. ... д. філол. н. Київ, 2003. $502 \mathrm{c}$.

4. Приходько А.М. Концепти і концептосистеми в когнітивно-дискурсивній парадигмі. Запоріжжя : Прем'єр, 2008. 332 с.

5. Beauvoir S. de. La force des choses. I-er volume. Paris : Gallimard, 1963. 384 p.

6. Beauvoir S. de. La force des choses. II-e volume. Paris : Gallimard, 1963. 512 p.

7. Beauvoir S. de. La force de l'âge. Paris : Gallimard, 1960. 693 p.

8. Beauvoir S. de. Tout compte fait. Paris : Gallimard, 1986. 640 p.

9. Daniel J. Le temps qui reste. Paris : Stock, 1973. $320 \mathrm{p}$.

10. Robert J. Les stars de mes nuits. Paris : Rocher, 1991. $168 \mathrm{p}$.

\section{REFERENCES}

1. Vorob'eva O.P. (1993) Lingvisticheskie aspekty adresovannosti khudozhestvennogo teksta [Linguistic aspects of the addressability of a literary text] (PhD Thesis), Moscow: Moscow State Linguistic University.

2. Galich A.A. (1991) Ukrainskaya pisatel'skaya memuaristika (Priroda, ehvolyuciya, poetika) [Ukrainian memoiristics (nature, evolution, poetry)] (PhD Thesis), Kyiv: Taras Shevchenko National University of Kyiv.

3. Kahanovska O.M. (2003) Tekstovi kontsepty khudozhnoi prozy: kohnityvna ta komunikatyvna dynamika (na materiali frantsuzkoi romanistyky $X X$ stolittia) [Text concepts in fiction: cognitive 
and communicative dynamics (based on French novelism of the twentieth century] (PhD Thesis), Kyiv: Kyiv National Linguistic University.

4. Prykhodko A.M. (2008) Kontsepty i kontseptosystemy $v$ kohnityvno-dyskursyvnii paradyhmi [Concepts and concept systems in the cognitive-discursive paradigm], Zaporizhzhia: Premier, $332 \mathrm{~s}$.

5. Beauvoir S. de. (1963) La force des choses. I-er volume. Paris : Gallimard, 384 p.
6. Beauvoir S. de. (1963) La force des choses. II-e volume. Paris : Gallimard, 512 p.

7. Beauvoir S. de. (1960) La force de l'âge. Paris : Gallimard, 693 p.

8. Beauvoir S. de. (1986) Tout compte fait. Paris : Gallimard, $640 \mathrm{p}$.

9. Daniel J. (1973) Le temps qui reste. Paris : Stock, $320 \mathrm{p}$.

10. Robert J. (1991) Les stars de mes nuits. Paris : Rocher, 168 p. 